\title{
Challenges of Developing Competencies in Students in Developing Contexts
}

\author{
Aamna Pasha ${ }^{1}$, Ajay Pinjani ${ }^{2}$, Ali Bijani ${ }^{2}$, Naveed Yousuf ${ }^{2}$ \\ ${ }^{1}$ Institute of Education - UCL, UK \\ ${ }^{2}$ Aga Khan University Examination Board, Pakistan
}

\begin{abstract}
The paper looks at the challenges of implementing a project-based learning approach for students of the middle school aimed at developing key 21st century skills through engagement with interdisciplinary projects developed around real world situations and problems. The programme was implemented across Pakistan for over 14,000 students over a course of 2 years. Challenges include a lack of understanding of what competencies are; the value of developing core skills and the assessment of these; in addition, the struggle of teachers in moving from being instructors to facilitators, in order, to allow the development of skills. The paper concludes with ways in which these challenges were addressed.
\end{abstract}

\section{Introduction}

The world's pressing problems seldom result from being unable to read and write; they result from people across different cultures, races, religions, and nations being unable to cooperate and address the world's problems, such as global warming, poverty, racism, international conflict and war [1]. The need of the time has brought forth discourse around 21st Century competencies as a response to the requisite of modernday education. Under this approach skills such as those of communication, collaboration, critical thinking, citizenship and the knowledge of global systems, and multiple perspectives are at the fore [2], [3]. Its importance is being realized in the education sector globally; a study conducted on seventeen OECD regions and countries has confirmed the inclusion of 21st century skills in their policy regulations for compulsory education [1].

Traditional classrooms, however, lack the learning environment necessary for the implementation of $21 \mathrm{st}$ century skills. The traditional learning environment requires fundamental change in favor of pupiloriented education that allows students to be more actively involved in their learning [4]. New standards for what students should be able to do must replace the basic skills and knowledge expectations of the past. To meet this challenge, schools must be transformed in ways that will enable students to acquire the sophisticated thinking, flexible problem solving, and collaboration and communication skills they will need to be successful in work and life [5]. Educational systems that strongly emphasize testing further limit the inculcation of competencies as teachers who address the challenges of high stakes testing limit students' range of skills and literacies needed in the modern world [6]. There is a need to employ modified techniques for testing and assessment that measure students' capacities effectively. Pakistan's educational system is a definitive example of such challenges and reflective of the need for the change in order to facilitate the development of 21 st century skills.

This paper describes the challenges of implementation of a programme run in over 100 private schools across Pakistan aimed at developing core competencies in middle school students. Teachers views at different occasions during the academic year were collated, in addition to facilitator observations during trainings to understand and explore the areas which teachers and students found challenging. Additionally, this paper looks at the mechanisms that were resultantly employed to ease these challenges with the aim of informing future programmatic design around 21st century skills in developing contexts.

\section{The Pakistani Context}

Pakistan currently has the largest percentage (64) of young people under the age of 30 , ever recorded in its history [7]. This massive youth population signals to a large emerging group that will be engaging with a complex, dynamic and interdependent world. Pakistan's ethnic, cultural and sectarian composition is diverse and its relations to the wider world is dynamic and complex. From the outset, Pakistan has remained centre stage through global affairs primarily due to its geographical positioning. The Islamic republic is neighbours with China to the north, Afghanistan and Iran to its west, India on the east with the Arabian Sea to the south. The subcontinents' independence from the British colonial rule was subsequently followed by the creation of Pakistan after partition with India in 1947. 
On the Educational front, Pakistan has committed to Education for All (EFA) and the Darkar Framework of Action and according to National Education Policy of Pakistan, 2009:

The objective of education is the development of a self-reliant individual, capable of analytical and original thinking, a responsible member of his community and, in the present era, a global citizen.

However, despite its policy and commitments, Pakistan lags in achieving the Millennium Development Goals (MDGs) [8] and is cited as one of Asia's worse systems of government-sponsored education [9]. Although the statement was a concluding remark from a research carried out in 1990 's, not much has improved till date. Across the country children score poorly in reading and mathematics across all provinces. More than half of the country's adult population is unable to read and write and the number of out of school children remains alarmingly high [10].

Similarly, poor conclusions have been derived about the quality of secondary schooling in Pakistan which faces several challenges. Education is largely defined as academic achievement and testing, and this holds true for other developing countries also that have demonstrated that "many classroom practices too often reduce teaching and learning to exactly the kind of mindless rule-following that makes students unable to make principled stand." [11] "Subjectivity, poor content coverage, use of single textbooks for examination preparation, administrative shortcomings, malpractices and rote memorization are listed as major shortfalls of the examinations system in Pakistan" [12] As a consequence, the enabling competencies imprinted in the policy are largely ignored in day to day teaching and learning. The result of adopting this outdated pedagogy is that the learning outcomes of students throughout Pakistan are weak. Furthermore, schools in Pakistan are dedicated to the dispersion of knowledge, taking little interest in teaching skills such as problem solving \& decision making and values such as civic mindedness \& critical consciousness in their classrooms [13].

\section{About the Aga Khan University - Examination Board}

In the Pakistani educational system, schools conduct their own examinations and promote students from one grade to the next until grade 8 . Grade 9 onwards, students appear for external examinations that take place either at a provincial or federal level and award certification for the same. There are 27 boards operational at regional levels alongside 2 international boards that offer examinations at the secondary and higher secondary level. While the international boards are costly, local boards grapple with issues of fairness and reliability. The Aga Khan University Examination Board (AKU-EB) is Pakistan's first private autonomous national examination body established by the Aga Khan University in August 2003 in accordance with Ordinance of the Government of Pakistan. The need for its establishment was felt considering the lack of affordable, transparent and fair assessments at the secondary (SSC) and higher secondary (HSSC) school certification level. AKU-EB's primary purpose is to improve the quality of education by providing high quality examinations across the country in accordance with the National Curriculum of Pakistan.

AKU-EB enrols students from diverse geographic ethnic, religious and socio-economic backgrounds and places emphasis on concept-based learning. Students are assessed on their understanding and application of knowledge. There is a focus given to encourage teaching and learning to move away from rote memorization towards, deeper understanding of concepts and higher order cognitive skills.

\section{Framework of the Program}

Because of an educational system that places a heavy emphasis on rote memorization, students were ill prepared as critical thinkers and lacked a range of fundamental skills such as that of communication or information gathering. It was identified that teachers struggled to teach for higher cognitive levels and had a dependence on traditional teaching methodologies. This was the key driver for the development of the Middle School Programme (MSP) that was aimed to help schools to offer an experiential learning programme at grade levels not driven by high stake assessment while also allowing teachers to experience a different pedagogical approach through projectbased learning. Grade 6 to 8 were chosen as the platform for the programme as at these grade levels, the uptake of the programme was more promising given the absence of high-stake assessment in these years. The assumption was that schools would be more willing to adopt and attribute time in the academic year to the implementation. A broad-based foundation of educational experiences at the middle school through project-based learning was seen to be a positive way to encourage the development of a wide range of competencies.

The Cdefop [19] of the European Commission defines competence as the "ability to apply learning outcomes adequately in a defined context. Competence encompasses cognitive elements as well as the functional aspects, interpersonal attributes and ethical values. In all the available frameworks competencies commonly referred to as 21 st century competencies or 21 st century skills are generally characterized as being transversal, that is they are not directly linked to a specific field; include knowledge, 
skills and attitudes and are associated with higher order skills and behaviours that develop the ability to cope with complex problems and unpredictable situations as cited in [14].

When identifying core competencies for focus in the programme, several frameworks were considered in light of Pakistan's context. Educational experts in the areas of Assessment and Teaching and Learning, reviewed frameworks/models that included the Partnership for 21st Century Learning that has guided the educational landscape around 21st Century Skills and that of the Assessment and Teaching of 21st Century Skills. The former broadly places skills under the three themes of: Life and Career skills; Learning and Innovation Skills; Information, Media and Technology skills while the later breaks down skills into 4 broad categories that include: Living in the World, Ways of Thinking, Ways of Working and Tools for Working. In addition, OECD's 21st Century sills and competencies for new millennium learners was examined that placed competencies under three dimensions: information, communication and ethics and social impact.

Looking at the contextual reality of the county, available resources and readiness of schools, teachers and students the following eight competencies were identified at the time of the designing of the programme: Listening, Reading and Observation skills, Information Gathering, Critical Thinking and Problem Solving, Communication Skills, Interpersonal Skills, Team Work, Responsibility, Creativity and Innovation.

Project based learning (PBL) was seen as the best vehicle through which the development of skills could take place. Jones, Rasmussen, \& Moffitt, [15] describe project-based learning as complex tasks that are authentic, curricular based, and involve students in problem solving, examination and decision making. Solomon, [16] expands the definition by including that PBL is often interdisciplinary and involves collaboration and reflection. As a student centric approach, it allows students the flexibility to navigate their learning, encourages responsibility, allows opportunity for team work and encourages students of different levels of ability to engage with the content at their own pace.

Studies have revealed that PBL has a positive effect on the development of higher-order thinking skills in specific groups of students [17]. Another study demonstrated that PBL positively impacts students, particularly low ability students who increased their use of such critical-thinking skills as synthesizing, evaluating, predicting, and reflecting. Further, PBL has been shown to foster collaboration skills in a variety of students [18]. This pedagogy has also been noted to have several positive effects on student content knowledge. Students immersed in PBL taught classrooms emerge with more useful, real- world content knowledge that can be applied to a variety of tasks [19]

Projects for the programme are developed each year for each of the three grade levels and are carefully aligned to the

national curriculum of Pakistan. Once enrolled into the Middle School Programme, schools receive an orientation about the objectives of the programme and the implementation process, while also providing space for teachers to communicate their inhibitions. Here teachers are encouraged to create an independent learning environment by switching from playing an instructive role to becoming a facilitator. Members from Teacher Development (TD) unit at AKU-EB commonly travel to school premises to provide training in situated practice. The orientation has a further advantage of allowing the TD team to explore and understand the diverse contexts in which the programme is being implemented, which also helps to provide more appropriate ongoing support throughout the year. Teachers also receive a Teacher's Guide to refer to throughout the year for each project. Once project implementation begins, an Ongoing Support structure is put in place to facilitate and address challenges that emerge from practice throughout the academic cycle.

After the completion of projects at the end of the academic year, an Annual Teacher Meeting is organized where teachers from three participating schools from the same region are invited. The purpose of the meeting is to provide a platform where constructive dialogue takes place, experiences are shared amongst schools, student projects are collectively reviewed, and a culture of sharing is strengthened. The TD team recognized the need to be informed of the challenges experienced to continue to improve and enhance the projects developed and to ensure that the optimum opportunity for competency development was being provided. Given the multiplicity that exists from one school to another in Pakistan in terms of resource availability, teacher proficiency, acceptability of new methodology and student readiness we felt it important to cognize the challenges that could further enrich support to the schools. This was a twofold task: strengthening teachers' implementation of project-based learning and enhancing their understanding of competency assessment. Given that project-based learning was a new pedagogy for most teachers in Pakistan, gaps in implementation were anticipated. Additionally, we recognized that understanding of what competencies are and how they are assessed would be challenging for teachers as the use of a rubric is also a relatively new form of assessment. The second core aim was therefore to further develop their skill of observational assessment.

In the year 2015 - 2016 the programme started in 43 schools with a total of 5804 students. These schools located in 14 cities in 3 different provinces of 
Pakistan namely, Sindh, Punjab and Gilgit Baltistan. A total number of 262 teachers participated in the Annual Teacher Meeting (ATM) conducted at the end of the academic cycle for MSP. In 2016 - 2017 the programme extended to reach 72 schools with 9028 students enrolled across Pakistan. The distribution of male to female students was almost equal. The schools were spread in 16 different cities of 4 different provinces of Pakistan that now also included Khyber Pakhtunkhwa. In this year, a total of 368 teachers took part in the ATM.

A feedback form was implemented at the end of each orientation probing teachers to share what challenges they think they might face and what they thought the strength of the programme was. All conversations regarding the challenges, experiences, and achievements taking place during ongoing support were documented and logged. At the end of the Annual Teacher Meeting a detailed feedback form was filled by each teacher that explored their experience of implementing the programme. In addition, trainer observations were gathered after each training session to add to the understanding of what concerns were being raised and shared. Collectively these responses and observations were thematically grouped and analysed to inform this paper.

\section{Challenges}

Over the course of rollout and implementation of this programme, several challenges came forth. Foremost was the realization of the lack of understanding of what competencies are. Teachers at lacked a basic understanding of what team work would entail or what critical thinking encompassed. Because of the lack of awareness of what competencies were, there was little thought on how these competencies could be developed in students.

More concerningly, the value of competencies in the education of a student was absent. For a great part, it was seen to take time away from teaching the core curriculum and being an added burden to the already extensive syllabus that teachers had the task of covering. This could be attributed to the fact that in a lot of schools, teachers' appraisals are linked to the academic success of their students; as a result of this, focusing on competency development was seen as a distraction from focusing on what they believed matters most: summative assessment.

Consequently then, a programme that did not have any kind of summative assessment was difficult to understand for many teachers. There were extensive questions on how performance could be measured without awarding grades and what that would mean for student motivation and interest in actually doing the projects. During the ongoing support it was discovered that some schools were attributing marks as classwork for the project while others used the score of each competency to hold a weightage in the students overall summative score. These schools were particularly apprehensive about the quality of work students would submit and the motivation they would have in the absence of awarding marks.

Possibly the most widespread challenge was the struggle of teachers in moving from being instructors to facilitators, in order, to allow the development of skills. Teachers most often did not perform their role as a facilitator who scaffolds and instead dictated some of the process of the projects.

PBL and resultantly, the programme is process driven rather than product cantered. For many students and teachers alike, the product was always valued more than the process. So, the final report, poster or other final task that tied all of the learning together at the end of each project was given far more importance, than the steps the student undertook to reach the end. On several occasions it was observed that although the project had been completed, rough drafts of the process, the discussion points from group dialogue between pupils, brainstorming notes, research summaries and other such process related documents were not presented. Both a cause and an effect of this was that teachers considered there to be one correct answer or conclusion for each project. Teachers were often requesting for the staff of AKUEB to 'check' the work and validate if the answer was correct. The notion that there could be multiple answers and perspectives and multiple ways in which students complete their tasks was largely missing.

Another essential aspect of the programme was the interdisciplinary nature of the projects. To fulfil the task assigned, students were expected to navigate through the domain of multiple subjects. However due to administrative easiness and lack of understanding of the benefits of teaching interdisciplinary concepts, more often only one subject teacher was assigned to facilitate the implementation of a project. Consequently, during year end meetings, many teachers did not recall the project by its name or its driving question but by the subject they felt it was associated to.

The availability of time was one of the most prominent challenges posed by teachers. There were several reasons for this: foremost, MSP projects were seen as being unconventional process-oriented tasks hence time consuming to complete. Secondly, teachers were not used to the practice of observing competency development among students and so felt they had to spend a lot of time reading the rubric and thinking through the score they assigned each student. Thirdly, teachers lacked the ability to link the content and concepts covered in the projects with the syllabus at hand. As a result, they ran the programme in parallel to their regular teaching classes rather than using it as a mechanism to enhance their own teaching. Teachers, thus, often complained of how time consuming the execution of the programme was. This situation was exasperated by school leadership 
that was unclear of the demand of the programme and questioned teachers on their time investment in completing the core syllabi.

A mammoth challenge at the beginning of the programme was the lack of originality in students work as very little variation was seen in the work presented. Sometimes a whole grade level in a school would have similar, if not exact end products and an equally similar process being submitted. The cause in some schools was identified to be teachers' lack of understanding of the value and importance of originality of work. In other scenarios the root was acknowledged stem from other challenges such as time management which resulted in teachers often dictating or encouraging students to replicate in an attempt to speed up the process.

\section{Addressing Challenges}

To address these challenges a number of stages were built in the training and support. Foremost training included a structured time and reflection component for teachers to identify competencies they required from their own working experience. This process was valuable for teachers to recognize the importance of competencies in every individual's life, not just for students. Once this was achieved, teachers were asked to analyze whether the problems they faced could be addressed through specific content knowledge. Almost always teachers identify solutions to their own struggles to stem from an attitude, a behavior, a skillset or a mindset. This realization is fundamental to getting teachers to understand the essence of the program and this buy in was paramount at the beginning of any interaction with a teacher.

The second step was to encourage attendees to think of ways in which skills and attitudes can be developed in students. Most often, teachers naturally arrive at having student's role play situations or scenarios that would encourage their competencies to be brought to the forefront and highlighted. It is from here that the program itself is introduced to help teachers understand that the purpose of the projects is to do exactly what they have identified. The third essentially crucial stage is the understanding of the concept of interdisciplinary projects and its importance. Again, teachers are asked to share and then deconstruct a situation or an activity by identifying the subject from which the situation or problem stem. Teachers are never able to identify just one subject that a problem/ scenario stem from. This allows the trainer to explain the importance of interdisciplinary thinking and the connection between ideas and concepts. The stage also involves walking participants through one project in its entirety for them to see what interdisciplinary looks like in a project. These three stages helped establish quite firmly the value of developing competencies and of an interdisciplinary approach. It also helped to lay the base for project-based learning which could then be built upon with regards to the technicalities of execution.

With the 'what' and the 'why' decisively agreed upon, the teachers then only required comfort and guidance on ways in which to manage time in an academic year. For this, teachers were asked to study their school syllabi along with the projects and identify when each project could be introduced based on when the concept was being introduced in their teaching year. They were oriented to appreciate the program not as an addition to their teaching but as something that would enrich the classroom experience. During ongoing support this aspect needed continuous reiteration. It also resulted in the teacher development team urging the attendance of the school leadership in the trainings so that leadership was better able to understand the demands of the program and better support the teachers in the endeavor.

Teachers' apprehension in executing a program which did not have a formal assessment or ascribe scores, or grades could only be addressed once the program had begun. Because project-based learning is a relatively new phenomenon in this context, students' level of engagement was high and this was recognized during the implementation. Teachers were able to see the interest and motivation of the students despite an absence of testing.

The lack of originality of student's work was first identified in the Annual Teachers Meeting that took place in the first year of the program. In subsequent years a more proactive approach was taken at the beginning of the year to stress to teachers the importance of making sure students were facilitated to present original work. It was hoped that by addressing time management concerns and helping teachers understand their role of facilitators this challenge would subsequently resolve itself. This could also be the result of a testing culture in which there is always just one correct answer. There is we argue, a need to more strongly emphasize the value of diversity not just in the program but in the educational system at large.

One of the greatest challenges and the hardest one to address was having teachers understand their role in the program and have them move from a teacher led to a student led approach. This continues to be an ongoing challenge to address. The first step was to introduce to teachers the art of scaffolding to help them shift from 'telling' answers to leading students to them. The second was to pose scenarios and have teachers identify if the individual was acting as a facilitator or an instructor. This process helped teachers to understand what it means to be a facilitator and were also able to reflect on their own practices. 


\section{Conclusion}

The Pakistani educational context is complex because of the diversity that exists and the heavy emphasis on traditional methods of teaching and learning that offer little room and sometimes great resistance to change. Design and development of programs like these therefore, need to be cognizant of and develop strategies to mitigate the challenges faced. All the strategies adopted to address challenges faced have and will remain an ongoing process as the idea of competency focused project-based learning is a paradigm shift for both schools and teachers. Resultantly, there is a need to attribute significant time for those implementing the program to fully understand the essence of it and their role in the process. Most often, going through the process is the greatest way to inhibit teachers' apprehensions and have them learn by doing. In its third year, the program enrolls a little over 12,000 students across Pakistan with $75 \%$ of the new schools enrolled in the 2017-2018 cycle have come to the program as result of having heard of its value from other schools in their communities or from students that are going through the program. This speaks not just to the need of such programs in similar contexts but also to their effectiveness that can be greatly acknowledged and understood if adequate mechanisms are put in place to alleviate challenges.

\section{References}

[1] Ananiadoui K, Claro M. 21st Century Skills and Competences for New Millennium Learners in OECD Countries. Paris; $2009 . \quad$ doi: https://doi.org/10.1787/218525261154

[2] Coomans A. Teaching for Global Competence in a Rapidly Changing World. Vol 70.; 2018. doi:10.1007/BF00277757

[3] Pike G. Global Education. In: Arthur J, Davies I, Hahn $\mathrm{C}$, eds. The SAGE Handbook of Education for Citizenship and Democracy. London: SAGE Publications Ltd; 2008:468-481.

doi:

http://dx.doi.org/10.4135/9781849200486

[4] Bransford J d., Brown A., Cocking R. How People Learn. Brain, Mind, Expereince and School. Washington DC: National Academy Press; 2000. doi:10.4135/9781483387772.n2

[5] Binkley M, Erstad O, Herman J, et al. Defining TwentyFirst Century Skills. In: Assessment and Teaching of 21st Century Skills. Dordrecht: Springer Netherlands; 2012:1766. doi:10.1007/978-94-007-2324-5_2

[6] Au WW. Devising inequality: A Bernsteinian analysis of high-stakes testing and social reproduction in education. $\mathrm{Br} \quad \mathrm{J}$ Sociol Educ. 2008;29(6):639-651. doi:10.1080/01425690802423312
[7] Najam A, Bari F. Pakistan National Human Development Report 2017. Islamabad, Pakistan; 2017.

[8] Khan N, Amin N, Kakli M., Piracha Z., Zia M. Pakistan Education Statistics 2015-2016. Vol 24. Islamabad; 2017.

[9] Warwick DP, Reimers F. Hope or Despair? : Learning in Pakistan's Primary Schools. Praeger; 1995. https://eric.ed.gov/?id=ED390563. Accessed February 22, 2019.

[10] Ministry of Federal Education \& Professional Training. Pakistan - National Education Policy Framework 2018.; 2018.

[11] Westheimer J. What Kind of Citizen? Democratic Dialogues in Education. Educ Canada. 2008;48(3):6-10.

[12] Christie T, Afzaal M. Rote memorization as a sufficient explanation of secondary school examination achievement in Pakistan: An empirical investigation of a widespread assumption. In: IAEA International Conference "Assessment and the Future Schooling and Learning."; 2005.http://examinationboard.aku.edu/aboutakueb/whatsne wateb/Documents/IAEA05.pdf.

[13] Dean BL. Citizenship education in Pakistani schools: Problems and possibilities. Int $\mathrm{J}$ Citizsh Teach Educ. 2005;1(2):35-55. doi:10.1080/0965975960040303

[14] Voogt J, Roblin NP. A comparative analysis of international frameworks for 21 stcentury competences: Implications for national curriculum policies. J Curric Stud. 2012;44(3):299-321. doi:10.1080/00220272.2012.668938

[15] Jones BF, Rasmussen CM, Moffitt MC. Real-Life Problem Solving: A Collaborative Approach to Interdisciplinary Learning. Washington DC; 1997. doi:10.1037/10266-000

[16] Solomon G. Project-Based Learning: A Primer. Vol 23.; 2003.

[17] Mergendoller JR, Maxwell NL, Bellisimo Y. The Effectiveness of Problem-Based Instruction: A Comparative Study of Instructional Methods and Student Characteristics. Interdiscip J Probl Learn. 2006;(2):1. doi:10.7771/1541-5015.1026

[18] Horan C, Lavaroni C, Beldon P. Observation of the Tinker Tech Program students for critical thinking and social participation behaviors. Novato, CA Buck Inst Educ. 1996; 18 .

[19] Bradley-Levine J, Mosier G. Literature Review on Project-Based Learning. http://cell.uindy.edu/wpcontent/uploads/2014/07/PBL-Lit-Review_Jan14.2014. pdf. Accessed February 22, 2019. 